\title{
Acoustical Investigation of Adhesion in Liquid Metal/Ceramic Interfaces
}

\author{
Zakaria Hadef*, Abdellaziz Doghmane, Kenza Kamli and Zahia Hadjoub \\ Laboratoire des semi-conducteurs, département de physique, faculté des sciences, \\ Université Badji-Mokhtar, Annaba, BP 12, DZ-23000 Alegria; \\ zaki_hd2013@yahoo.fr, a_doghmane@yahoo.fr, kenza_kamli@yahoo.fr, z_hadjoub@yahoo.fr
}

\begin{abstract}
Objectives: The principal objective is to define a new acoustical investigation of interfacial adhesion in liquid metal/ceramic systems based on the study of plate acoustical wave propagation in these interfaces. Methods/Statistical Analysis: 1. Sessile drop technique was used to determine the work of adhesion of liquid metal/ceramic systems using the Young-Dupré equation. This procedure based on the recorded images of liquid drops used for measurements of surface tension $(\gamma \mathrm{LV})$ and contact angle $(\theta)$. 2. Experimental values of sound velocities (c) have been taken from Blairs. 3. Acoustic impedances have been calculated using the following equation $Z=\rho$ c. Findings: The most important results obtained in this study are: 1 . Linear correlation between the work of adhesion of liquid metals/ceramic structures and the sound velocity of corresponding liquid metals. 2. The possibility of determining the unknown surface tension as function of sound velocity of liquid metals and vice versa. 3. Strong dependence of the work of adhesion slope parameter for several ceramic materials on the acoustic impedance of the corresponding ceramics. 4. Interpretation of the wave propagation nature in the liquid metal/ceramic interfaces according to the existence and the excess of the interfacial bonding. 5. New approach of the interfacial phenomenon has been given and explain. Application/Improvements: 1. Fabrication of metal-ceramic composite materials. 2. ThermalBarrier Coatings (TBC). 3. Hard TiN coating. 4. Photovoltaic materials. 5. Functional components in microelectronics.
\end{abstract}

Keywords: Adhesion, Ceramics, Interfaces, Liquid Metals, Sound Velocity

\section{Introduction}

Metalized ceramic are playing a major role in several modern applications ${ }^{\underline{1}}$ such as metal-ceramic joining, metal-matrix composites, thin metal films on ceramic substrates ${ }^{2}$, TBC $\stackrel{3}{=}$, hard TiN-coating ${ }^{4}$, photovoltaic materials $s^{5}$ and as functional components in microelectronics ${ }^{6}$. The performance is directly related to the nature of the metal/ceramic interfaces.

The most important characteristics of these materials are their high-impact energy-absorption capacity, dimensional stability, thermal and electrical conductivity, low and controllable density and the large internal surface area. However, they could undergo a severe problem consisting of poor adhesion at metal/ceramic interfaces. This is why an understanding of the adhesion mechanism is needed in order to control the nature of the interfacial bonding and the determination of the reversible work necessary to damage these interfacial bonds $\frac{7-12}{}$.

Furthermore, the optimization of metal/ceramic interfacial adhesion by non-destructive techniques is crucial to the applications of these materials. In this context, various ultrasonic methods are established for the characterization of the metal/ceramic interfaces ${ }^{13}$.

*Author for correspondence 
In the liquid metals, the sound propagation is done transversely with a characteristic velocity; there is no matter transfer of but only energy transfer ${ }^{14,15}$. This acoustic wave does not depend only on the elastic properties of this liquid metal, but it is strongly affected by the properties of the interface with the ceramic substrate. The weakly or strongly adherent regions have different responses. This means that a change in the properties of the adhesion must result in a change of the velocity of the surface waves in the ceramic ${ }^{\frac{15}{5}}$.

In this paper, a new acoustic approach is suggested to interpret the interfacial adhesion in the non-reactive metal/ceramic systems. Discussions will be made on the relation between sound propagation and the nature of bonding of metals with several ceramic materials.

\section{Methodology}

The adhesion of the metal/ceramic system is the most important factor of all metal bonds. It is defined by the change in the free energies of two materials when they come into contact $\frac{16}{\text {. }}$.

The work of adhesion, $W_{a d}$, between the liquid metal and the ceramic can be expressed using the Young-Dupré equation relating the surface tension of the liquid metal above the melting temperature $\gamma_{\mathrm{LV}}$ and the measured equilibrium contact angle $\theta$ formed by the metal on the ceramic substrate as shown in Figure 1 ${ }^{\frac{17}{}}$ :

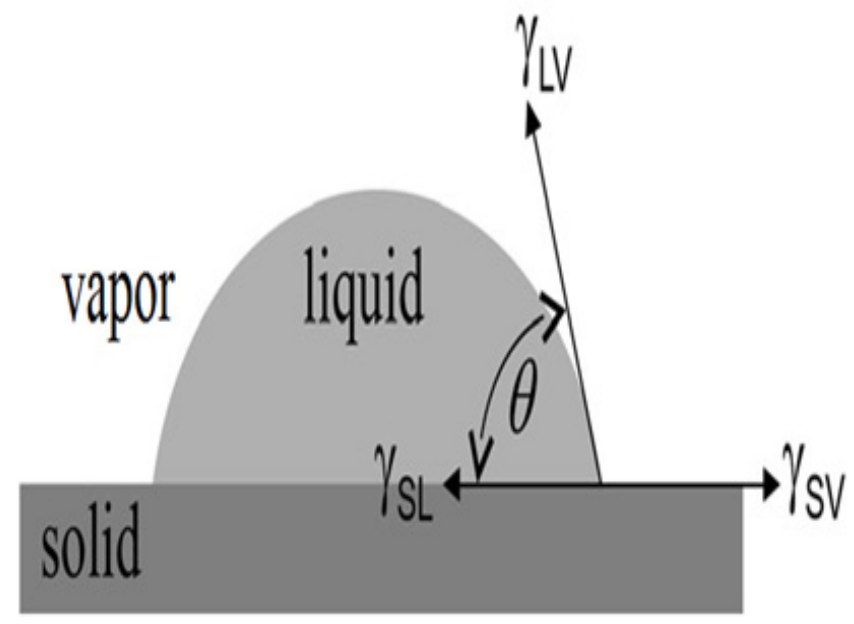

Figure 1. Schematic profile of a contact angle, $\theta$, in a solidliquid-vapor system, in equilibrium ${ }^{16}$.

$$
W_{a d}=\gamma_{L V}(1+\cos \theta)
$$

The work of adhesion $W_{a d}$ in metal/ceramic contact is generally written as the sum of different contributions of the interfacial interactions between two phases ${ }^{17}$ :

$W_{a d}=W_{\text {equil }}+W_{\text {non-equil }}$

$W_{\text {non-equil }}$ represents the non-equilibrium contribution to the work of adhesion. In the absence of chemical reactions this term does not appear. $W_{\text {equil }}$ represents the equilibrium contribution, which corresponds to nonreactive systems. This later can be expressed by two distinct terms:

$$
W_{\text {equil }}=W_{\text {chem-equil }}+W_{V D W}
$$

where $W_{\text {chem-equil }}$ is the adhesion energy between the two contact phases, which results from the establishment of the chemical equilibrium bonds obtained by the mutual saturation of the free valences of the surfaces in contact. The formation of these chemical bonds is not accompanied by the rupture of the interatomic bonds in metal/ceramic interface, which takes place in the chemical non-equilibrium systems.

$W_{V D W}$ represents the van der Waals interactions.

During the propagation of the ultrasonic waves, the particles undergo a sinusoidal vibratory displacement around their rest position. Consequently, their density varies by making regions appear denser and others less dense than when they are at rest. The ratio of these deletions and depressions by the acoustic velocity defines the notion of impedance. According a normal incidence of the acoustic wave on a flat surface, the acoustic impedance $Z$ expressed by:

$$
Z=\rho c
$$

Following the various calculations derived from this equation ${ }^{18}$ we will use the general form of the acoustic impedance $Z$ as a function of the density $\rho$ and the Young modulus $E$ of the transverse acoustic wave: 


$$
Z=(\rho E)^{1 / 2}
$$

The stresses imposed by a liquid on the surface of the ceramic are mainly due to the viscosity. The liquid metal/ ceramic coupling results in radiation in the liquid of a highly damped transverse wave. The acoustic reflection coefficient at the interface is written as:

$$
R=\left(Z_{L M}-Z_{C}\right) /\left(Z_{L M}+Z_{C}\right)
$$

Where $Z_{L M}$ and $Z_{C}$ are the impedances of the liquid metal and ceramic
The reflection coefficient $R$ makes it possible to determine the transmitted energy as a function of the impedances at the liquid metal/ceramic interface. This energy is determined by its transmission coefficient, which is defined as follows:

$$
T=1-R
$$

\section{Results and Quantification}

A new acoustic model is proposed to interpret the work of adhesion in non-reactive metal/ceramic systems. In this model, the energy transfer by the sound propagation

\begin{tabular}{|c|c|c|c|c|c|c|}
\hline Ceramic & $\mathrm{E}_{\mathrm{C}}(\mathbf{G P a})^{(14)}$ & $\rho_{C}\left(\mathbf{K g} / \mathbf{m}^{3}\right)^{(14)}$ & Metal & Atmosphere & $W_{a d}\left(\mathrm{~m} J / \mathbf{m}^{2}\right)$ & Ref. \\
\hline \multirow{14}{*}{ AlN } & \multirow{14}{*}{350} & \multirow{14}{*}{3260} & $\mathrm{Ag}$ & Vacuum & 630 & $\underline{23}$ \\
\hline & & & $\mathrm{Al}$ & Vacuum & 1136 & $\underline{23}$ \\
\hline & & & $\mathrm{Au}$ & Vacuum & 650 & $\underline{23}$ \\
\hline & & & $\mathrm{Co}$ & Vacuum & 1270 & $\underline{23}$ \\
\hline & & & $\mathrm{Cu}$ & Vacuum & 1060 & $\underline{20}$ \\
\hline & & & $\mathrm{Fe}$ & Vacuum & 1320 & $\underline{23}$ \\
\hline & & & $\mathrm{Ga}$ & Vacuum & 750 & $\underline{23}$ \\
\hline & & & $\mathrm{Ge}$ & Vacuum & 811 & $\underline{23}$ \\
\hline & & & In & Vacuum & 448 & $\underline{23}$ \\
\hline & & & $\mathrm{Ni}$ & Vacuum & 1305 & $\underline{23}$ \\
\hline & & & $\mathrm{Pb}$ & Vacuum & 203 & $\underline{23}$ \\
\hline & & & $\mathrm{Pd}$ & Vacuum & 858 & $\underline{23}$ \\
\hline & & & $\mathrm{Si}$ & Vacuum & 1058 & $\underline{23}$ \\
\hline & & & Sn & Vacuum & 461 & $\underline{20}$ \\
\hline
\end{tabular}

Table 1. . Young's moduli $\mathrm{E}_{\mathrm{c}}$ and densities $\rho_{\mathrm{C}}$ of ceramics and experimental values work of adhesion $\mathrm{W}_{\mathrm{ad}}$ in various metal/ceramic systems 
Table 1 Continued

\begin{tabular}{|c|c|c|c|c|c|c|}
\hline \multirow{9}{*}{$\mathrm{Al}_{2} \mathrm{O}_{3}$} & \multirow{9}{*}{400} & \multirow{9}{*}{3980} & $\mathrm{Al}$ & Vacuum & 948 & $\underline{24}$ \\
\hline & & & $\mathrm{Au}$ & Vacuum & 577 & $\underline{24}$ \\
\hline & & & $\mathrm{Fe}$ & Vacuum & 1202 & $\underline{24}$ \\
\hline & & & $\mathrm{Ga}$ & Vacuum & 537 & $\underline{24}$ \\
\hline & & & In & Vacuum & 335 & $\underline{24}$ \\
\hline & & & $\mathrm{Ni}$ & Vacuum & 1191 & $\underline{24}$ \\
\hline & & & $\mathrm{Pb}$ & Vacuum & 218 & $\underline{24}$ \\
\hline & & & $\mathrm{Si}$ & Vacuum & 876 & $\underline{24}$ \\
\hline & & & $\mathrm{Sn}$ & Vacuum & 305 & $\underline{24}$ \\
\hline \multirow{4}{*}{$\mathrm{BeO}$} & \multirow{4}{*}{390} & \multirow{4}{*}{3010} & $\mathrm{Cu}$ & $\mathrm{Ar}$ & 600 & $\underline{20}$ \\
\hline & & & $\mathrm{Fe}$ & $\mathrm{He}$ & 717 & $\underline{20}$ \\
\hline & & & $\mathrm{Ni}$ & vacuum & 680 & $\underline{20}$ \\
\hline & & & $\mathrm{Pb}$ & vacuum & 130 & $\underline{17}$ \\
\hline \multirow{4}{*}{$\mathrm{BN}$} & \multirow{4}{*}{34} & \multirow{4}{*}{3487} & $\mathrm{Au}$ & vacuum & 205 & $\underline{21}$ \\
\hline & & & $\mathrm{Cu}$ & vacuum & 345 & $\underline{21}$ \\
\hline & & & $\mathrm{Si}$ & vacuum & 364 & $\underline{21}$ \\
\hline & & & $\mathrm{Sn}$ & vacuum & 128 & $\underline{21}$ \\
\hline \multirow{3}{*}{$\mathrm{CoO}$} & \multirow{3}{*}{191} & \multirow{3}{*}{9423} & Co & Ar & 2526 & $\underline{2}$ \\
\hline & & & $\mathrm{Ni}$ & Ar & 2705 & $\underline{2}$ \\
\hline & & & $\mathrm{Sn}$ & vacuum & 994 & $\underline{2}$ \\
\hline \multirow{5}{*}{$\mathrm{MgO}$} & \multirow{5}{*}{307} & \multirow{5}{*}{3580} & $\mathrm{Ag}$ & Ar & 421 & $\underline{21}$ \\
\hline & & & $\mathrm{Fe}$ & vacuum & 820 & $\underline{21}$ \\
\hline & & & In & vacuum & 172 & $\underline{20}$ \\
\hline & & & $\mathrm{Ni}$ & $\mathrm{He}$ & 585 & $\underline{21}$ \\
\hline & & & $\mathrm{Sn}$ & vacuum & 278 & $\underline{20}$ \\
\hline
\end{tabular}


Table 1 Continued

\begin{tabular}{|c|c|c|c|c|c|c|}
\hline \multirow{4}{*}{$\mathrm{NiO}$} & \multirow{4}{*}{220} & \multirow{4}{*}{6670} & $\mathrm{Ag}$ & $\mathrm{Ar}$ & 1267 & 22 \\
\hline & & & $\mathrm{Cu}$ & $\mathrm{Ar}$ & 1738 & 22 \\
\hline & & & $\mathrm{Ni}$ & $\mathrm{Ar}$ & 2652 & 22 \\
\hline & & & Sn & vacuum & 921 & 25 \\
\hline \multirow{3}{*}{$\mathrm{TiO}$} & \multirow{3}{*}{387} & \multirow{3}{*}{4950} & $\mathrm{Au}$ & vacuum & 1858 & 20 \\
\hline & & & $\mathrm{Cu}$ & vacuum & 1581 & 20 \\
\hline & & & $\mathrm{Ni}$ & vacuum & 2652 & 20 \\
\hline \multirow{3}{*}{$\mathrm{SiO}_{2}$} & \multirow{3}{*}{72} & \multirow{3}{*}{2600} & $\mathrm{Au}$ & vacuum & 165 & 21 \\
\hline & & & $\mathrm{Cu}$ & vacuum & 390 & 21 \\
\hline & & & Sn & vacuum & 253 & 25 \\
\hline \multirow{3}{*}{$\mathrm{ZnO}$} & \multirow{3}{*}{125} & \multirow{3}{*}{5606} & $\mathrm{Ag}$ & $\mathrm{Ar}$ & 747 & 22 \\
\hline & & & $\mathrm{Cu}$ & $\mathrm{Ar}$ & 1060 & 22 \\
\hline & & & Sn & $\mathrm{Ar}$ & 481 & 22 \\
\hline \multirow{3}{*}{$\mathrm{ZrO}_{2}$} & \multirow{3}{*}{150} & \multirow{3}{*}{5600} & $\mathrm{Ag}$ & vacuum & 446 & 26 \\
\hline & & & $\mathrm{Cu}$ & Vacuum & 594 & 26 \\
\hline & & & $\mathrm{Pb}$ & vacuum & 114 & 26 \\
\hline
\end{tabular}

is assured by the existence and the excess of the interfacial bounds between a metal and a ceramic. The relevant parameters determining the work of adhesion of a metal/ ceramic system have been found to be the sound propagation velocity in liquid metal and the acoustic impedance of the solid ceramic.

Detailed experimental results of the work of adhesion for various metal/ceramic systems are summarized in Table 1. It should be noted that the criterion of liquid metals and given ceramics selected in this investigation must have the experimental $W_{a d}$ values of at least three different contacting metals available in the literature.
Figure 2 reveals that the work of adhesion of different liquid metals/aluminium nitride $(A l N)$ interfaces increases linearly when the sound propagation velocities $c$ of the corresponding metal increases.

It is thus important to define a new interfacial characteristic, which defines the energy transfer strength by the interfacial bounds to the ceramic phase, depending on the stability and the strength of the interfacial adhesion between different metals in contact with the ceramic, that is the slope parameter of the work of adhesion $\xi=\mathrm{d} W_{a d} l$ $\mathrm{d} c$. Similar idea was used by ${ }^{19}$ for the same systems but for the dependence of the work of adhesion and the electronic 


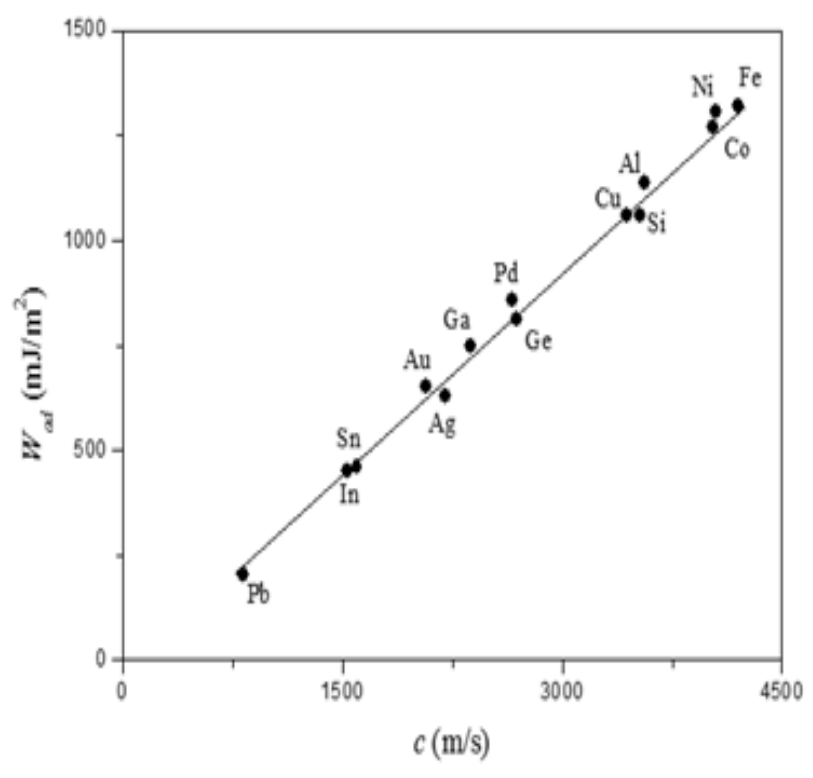

Figure 2. Correlation between work of adhesion $W_{a d}$ for different liquid metal/AlN systems and sound velocities $\mathrm{c}$ of corresponding liquid metals $\stackrel{27}{ }$.

density $\mathrm{n}_{\mathrm{ws}}$, which is responsible of the electronic transfer between the metallic phases and the ceramics. Therefore, the electronic density allows the formation of the interfacial bonds whether in excess or in deficit depending on the type of the ceramic.

The linear correlation of the points presented in Figure 2 yields a $\xi$ value of $0.312 \mathrm{~mJ} . \mathrm{s} / \mathrm{m}^{3}$ for aluminium nitride. These results, together with the $\xi$ values obtained for other solid ceramic materials are given in Table 2.

It is important to note that, the $W_{a d}$ values for the selected liquid metal/ceramic systems exhibit a good convergence as a function of the sound velocity of several liquid metals on a ceramic, as indicated by the values of the regression coefficients given in Table 2.

In Figure 3 the work of adhesion slope parameter $\xi$ values for different ceramics are plotted as a function of the acoustic impedance $Z_{c}$ of the corresponding ceramics. It can be seen that the slope parameter $\xi$ stabilizes at about $0.185 \mathrm{~mJ} . \mathrm{s} / \mathrm{m}^{3}$ for $Z_{c}<33.10^{6} \mathrm{Kg} / \mathrm{m}^{2}$.s. When the acoustic impedances become greater than this value, $\xi$ increases sharply. For $Z_{c}>38.10^{6} \mathrm{Kg} / \mathrm{m}^{2} . \mathrm{s}$, $\xi$ seems to stabilize again, but at about $0.600 \mathrm{~mJ} . \mathrm{s} / \mathrm{m}^{3}$.

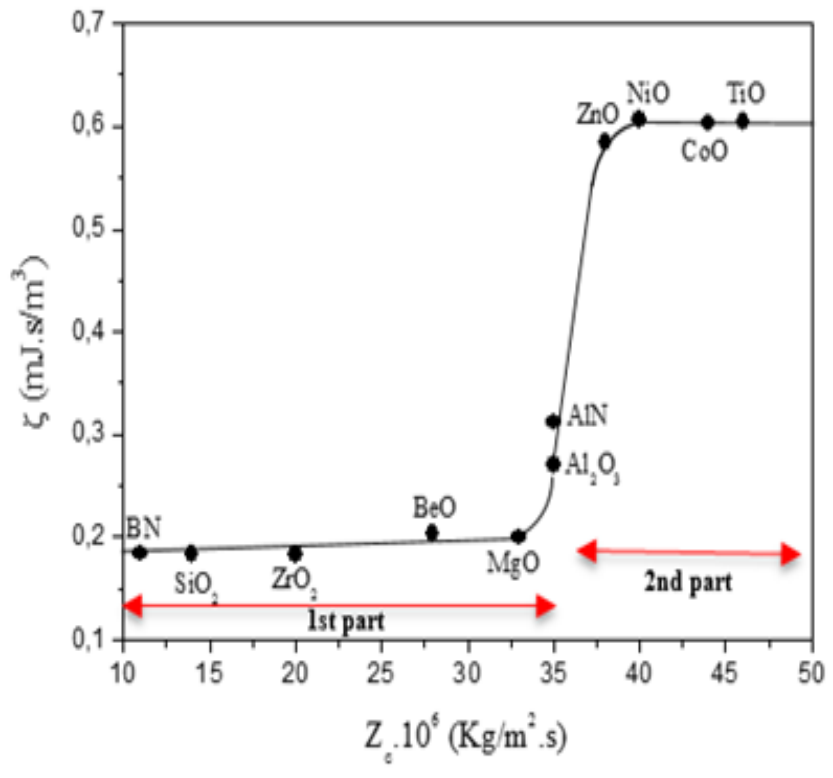

Figure 3. Work of adhesion slope parameter $\xi$ values of various ceramic materials as a function of the acoustic impedance $Z_{c}$ of the corresponding ceramics.

The excellent correlation between $\xi$ and $Z_{c}$ as presented in Figure 3 demonstrates that the work of adhesion slope parameter $\xi$ of liquid metal/ceramic interfaces depends only on the nature of the ceramic and not on the contacting liquid metals.

From Figure 3, we can distinguish two different cases of the variation of $\xi$ as a function of $Z_{c}$. The first part of this figure reveals that the reflection mode $R$ of the propagating acoustic wave in liquid metal becomes the most dominant according to the equation (6), for the impedance acoustic values of ceramics lower than that of AlN $\left(Z_{c}<Z_{\text {AIN }}\right)$. Therefore, the acoustic wave will be reflected in this middle and only a small part of the energy will be transmitted from the metal/ceramic interface because of a low interracial adhesion. The work of adhesion $W_{a d}$, in this part, is only resulting from the van der Waals interactions $W_{V D W}$, and the chemical equilibrium contribution $W_{\text {chem-equil }}$ is negligible $\underline{20-22}$.

The determination of $W_{V D R}$ values for different metal/ ceramic systems have been reported in different previous researches. For example, Naidich ${ }^{17}$ found a $W_{V D R}$ value of $350 \pm 150 \mathrm{~mJ} / \mathrm{m}^{2}$ for metal/oxide ceramic systems. 
Table 2. Slope parameter $\xi$ of work of adhesion for various solid ceramic materials and the coefficient of the linear regression $\mathrm{R}$

\begin{tabular}{|c|c|c|}
\hline Ceramic & $\boldsymbol{\xi}$ & $\boldsymbol{R}$ \\
\hline $\mathrm{AlN}$ & 0.312 & 0.9951 \\
\hline $\mathrm{Al}_{2} \mathrm{O}_{3}$ & 0.270 & 0.9780 \\
\hline $\mathrm{BeO}$ & 0.200 & 0.9991 \\
\hline $\mathrm{BN}$ & 0.184 & 0.9846 \\
\hline $\mathrm{CoO}$ & 0.606 & 0.9954 \\
\hline $\mathrm{MgO}$ & 0.203 & 0.9389 \\
\hline $\mathrm{NiO}$ & 0.604 & 0.9526 \\
\hline $\mathrm{TiO}$ & 0.603 & 0.9066 \\
\hline $\mathrm{SiO}$ & 0.183 & 0.9464 \\
\hline $\mathrm{ZnO}_{2}$ & 0.585 & 0.9880 \\
\hline $\mathrm{ZrO}$ & 0.183 & 0.9764 \\
\hline
\end{tabular}

The second case which corresponds to the values of ceramic acoustic impedance $Z_{c}$ greater than that of AlN $\left(Z_{\text {AlN }}<Z_{c}\right)$, shows that the transmission $T$ becomes the most dominant mode. The energy of the propagating wave in the liquid will be transmitted almost totally to the ceramic from metal/ceramic interface. In this limiting case, the work of adhesion $W_{a d}$ is approximately determined by the surface tension $\gamma_{\mathrm{LV}}$ of liquid metals as indicated by equation (1), and the work of adhesion slope parameter $\xi$ is proportional to $d \gamma_{L V} / d c$, that is the linear dependence of the surface tension of liquid metals on the sound propagation velocity of corresponding metal.

A linear correlation between $\gamma_{\mathrm{LV}}$ values of various liquid metals against $c$ is shown in Figure 4. An important point that can be interpreted from this figure is the possibility of determining the unknown surface tension as function of a known sound velocity of liquid metals and vice versa.

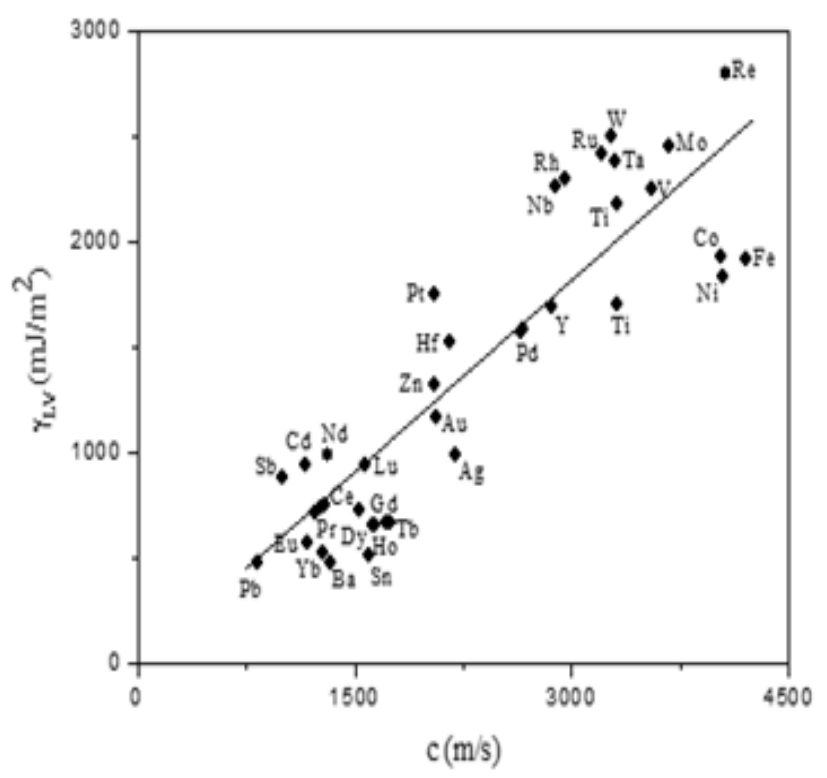

Figure 4. Correlation between the surface tension $\gamma_{\mathrm{LV}}$ of various liquid metals $s^{28}$ and the sound velocity $\mathrm{c}$ of the corresponding metals. 
The points presented in Figure 4 yields a surface tension slope parameter equal to $600 \mathrm{~mJ} . \mathrm{s} / \mathrm{m}^{3}$, which corresponds exactly to the upper limit of Figure 3. It is noted that this limit of has been already saturated for solid ceramic materials characterized by a dominant transmission energy mode, which explain the good interfacial adhesion.

\section{Conclusion}

In this paper, the work of adhesion of different liquid metals on a given ceramic was investigated. A new approach of the interfacial phenomenon was introduced. This novel interfacial phenomenon investigation was deduced after the study of $W_{a d}$ versus the sound velocity propagation of plate acoustical wave in corresponding metals which shows a linear correlation. Moreover, the work of adhesion slope parameter for several ceramic materials shows a strong dependence on the acoustic impedance of the corresponding ceramics. This result proves that this slope parameter depends only on the ceramic properties. Hence, the determined correlation between the slope parameter values and the acoustic impedance of various ceramic materials has a deep effect on the nature of the acoustical wave propagation (reflective or transitive) in metal/ceramic interfaces according to the existence and the excess of the interfacial bonding.

\section{References}

1. Wunderlich W. The atomistic structure of metal/ceramic interfaces is the key issue for developing better properties. Metals. 2014 Aug; 4(3):410-27. Crossref.

2. Li JG, Hausner H. Wetting and adhesion in liquid silicon/ ceramic systems. Materials Letters. 1992 Sep; 14(5-6):32932. Crossref.

3. Seiler P, Baker M, Roesler J. Multi-scale failure mechanisms of thermal barrier coating systems. Computational Materials Science. 2013 Dec; 80:27-34. Crossref.

4. Mayrhofer PH, Sonnleitner D, Bartosik M, Holec D. Sructural and mechanical evolution of reactively and non-reactively sputtered $\mathrm{Zr}-\mathrm{Al}-\mathrm{N}$ thin films during annealing. Surface \& Coatings Technology. 2014 Apr; 244:52-6. Crossref. PMid:24748705 PMCid:PMC3990427
5. Ekins-Daukes NJ, Lee K-H, Hirst L, Chan A, Führer M, Adams J, Browne B, Barnham KWJ, Stavrinou P, Connolly J. Controlling radiative loss in quantum well solar cells. Journal of Physics D: Applied Physics. 2013 Jun; 46(26):1-8. Crossref.

6. Imanaka Y, Amada H, Kumasaka F, Takahashi N, Yamasaki T, Ohfuchi M, Kaneta C. Nanoparticulated dense and stressfree ceramic thick film for material integration. Advanced Engineering Materials. 2013 Sep; 15(11):1129-35. Crossref.

7. Imhoff D, Laurent S, Colliex C, Backhaus-Ricoult M. Determination of the characteristic interfacial electronic states of $\{111\} \mathrm{Cu}-\mathrm{MgO}$ interfaces by ELNES. The European Physical Journal Applied Physics. 1999 Jan; 5(1):9-18. Crossref.

8. Groen HB, Kooi BJ, Vellinga WP, De Hosson J. Th. M. Highresolution transmission electron microscopy imaging of misfit-dislocation networks at $\mathrm{Cu}-\mathrm{MgO}$ and $\mathrm{Cu}-\mathrm{MnO}$ interfaces. Philosophical Magazine A. 1999; 79(9):2083101. Crossref.

9. De Hosson J. Th. M, Kooi BJ. Metal-ceramic interfaces: a microscopic analysis. Surface and Interface Analysis. 2001 Jul; 31(7):637-58. Crossref.

10. Zhukovskii YF, Kotomin EA, Fuks D, Dorfman S. First principles slab calculations of the regular $\mathrm{Cu}-\mathrm{MgO}$ (001) interface. Surface Science. 2004 Jun; 566-568:122-9. Crossref.

11. Matsunaka D, Shibutani Y. Electronic states and adhesion properties at metal-MgO incoherent interfaces: First-principles calculations. Physical Review B. 2008; 77(16):165435. Crossref.

12. Zhang Z, Long Y, Cazottes S, Daniel R, Mitterer C, Dehm G. The peculiarity of the metal ceramic interface. Scientific Reports. 2015 Jun; 5:11460. Crossref. PMid:26088014 PMCid:PMC4473597

13. Kar A, Sagar SP, Ray AK. Characterization of the ceramicmetal brazed interface using ultrasonic technique. Materials Letters. 2007 Jan; 61(19-20):4169-72. Crossref.

14. Briggs A. Acoustic Microscopy. Clarendon Press, Oxford; 1992.

15. Cros B, Vallat MF, Despaux G, Characterization by acoustic microscopy of adhesion in poly_ethylene terephtalate/ films coated by aluminium. Applied Surface Science. 1998; 126(1):159-68. Crossref.

16. Triantafyllou G, Irvine JTS. Wetting and interactions of $\mathrm{Ag}-\mathrm{Cu}-\mathrm{Ti}$ and $\mathrm{Ag}-\mathrm{Cu}-\mathrm{Ni}$ alloys with ceramic and steel substrates for use as sealing materials in a DCFC stack. Journal of Materials Science. 2016 Feb; 51(4):1766-78. Crossref. 
17. Naidich YV. The wettability of solids by liquid metals. Progress Surface Membrane Science. 1981; 14:353-84. Crossref.

18. Doghmane M, Hadjoub F, Doghmane A, Hadjoub Z. Approaches for evaluating Young's and shear moduli in terms of a single SAW velocity via the SAM technique. Materials Letters. 2007 Feb; 61(3):813-16. Crossref.

19. Li JG. Chemical trends in the thermodynamic adhesion of metal /ceramic systems. Materials Letters. 1995; 22(34):169-74. Crossref.

20. Li JG. Role of electron density of liquid metals and bandgap energy of solid ceramics on the work of adhesion and wettability of metal-ceramic systems. Journal of Material Science Letters. 1992; 11:903-5. Crossref.

21. Munoz MC, Gallego S, Beltran JI, Cerda J. Adhesion at metal-ZrO2 interfaces. Surface Science Reports. 2006 Sep; 61(7):303-44. Crossref.

22. Li JG. Wetting and interfacial bonding of metals with ionocovalent oxide. Journal of American Ceramics Society. 1992; 75:3118-26. Crossref.
23. Taranets NY, Naidich YV. Wettability of aluminum nitride by molten metals. Powder Metallurgy and Metal Ceramics. 1996 May; 35(5-6):74-8. Crossref.

24. Chatain D, Coudurier L, Eustathopoulos N. Wetting and interfacial bonding in ionocovalent oxide-liquid metal systems. Revue de Physique Appliquee. 1988 Jun; 23(6):1055-64. Crossref.

25. Stoneham AM, Dufy DM, Harding JH. in Designing ceramic interfaces II: Understanding and tailoring interfaces for coating, composite and joining applications, Peteves SD, editor, Committe of European Communities, Luxembourg; 1993. p. 573-82.

26. Sotiropoulou D, Nikolopoulos P. Work of adhesion in $\mathrm{ZrO} 2$ liquid metal systems. Journal of Materials Science. 1993 Jan; 28(2):356-60.Crossref.

27. Blairs S. Velocity of sound in liquid metals at melting temperature. Acta Acustica united with Acustica. 2006; 92(3):1-490.

28. Keene BJ. Review of data for the surface tension of pure metals. International Materials Review. 1993; 38(4):157-92. Crossref. 